to make domiciliary visits to monitor, and sometimes administer, home care, and also to help families to care for their elderly relatives. Greater public awareness and destigmatisation programmes will also be necessary. In-patient acute care will be in geriatric units in general hospitals. Such a system will minimise the back-log of admissions to homes for the elderly, which will be reserved for advanced cases.

\section{Research and publications}

In the absence of state financial support and because of the multiple wars that have devastated Lebanon, research work is still in its infancy. Nevertheless, some studies have, for example, found similar epidemiological characteristics in the Lebanese psychiatric population to those described in the literature for other countries. Other studies have examined the consequences of the war on psychiatric health, including post-traumatic stress disorder, benzodiazepine misuse and alcoholism. New publications have even appeared in the field of biological psychiatry.

\section{Conclusion}

Psychiatry in Lebanon is moving towards an increase in resources and capacities. The process of health sector reform will undoubtedly give psychiatry its place in the medical community.

\section{Reference}

Naja, W. J., Pelissolo, A., Haddad, R. S., et al (2000) A general population survey on patterns of benzodiazepine use and dependence in Lebanon. Acta Psychiatrica Scandinavica, 102, 429-431.

\title{
Reform of the mental healthcare system in Greece, 1984-2006
}

\section{Michael G. Madianos ${ }^{1}$ and George N. Christodoulou ${ }^{2}$}

\author{
'University of Athens, Department of Mental Health and Behavioural Sciences, Faculty of Nursing, \\ 42 Davaki Pindou str., 15773 Athens, Greece, email madianos@nurs.uoa.gr \\ ${ }^{2}$ Hellenic Psychiatric Association and Hellenic Centre for Mental Health and Research, 11 Papadiamantopoulou str.,
} 11528 Athens, Greece, email gchristodoulou@ath.forthnet.gr

G reece joined the European Community in 1981 and, 3 years later, the Commission of the European Communities provided financial and technical assistance under EEC Regulation 815/84 for the modernisation of the Greek mental healthcare system, with an emphasis on decentralisation and the development of community-based services, as well as the deinstitutionalisation of long-stay patients and improvement of conditions in public mental hospitals.

Over the past 20 years, public sector psychiatry in Greece has shown notable progress in deinstitutionalisation and the development of rehabilitation services. The role of the large mental hospitals has gradually diminished. In the area of primary care, however, progress has been rather slow. Utilisation and training of primary care physicians have not been given the priority they deserve and much remains to be done in the areas of primary psychiatric prevention and sensitisation of the public to mental health issues, in spite of notable exceptions (e.g. the Athens Mental Health Promotion Project, 2003).

In the early 1980s, psychiatric care in Greece was largely based on nine overcrowded, inadequately staffed public mental hospitals, and on a number of private mental hospitals (Christodoulou, 1970; Madianos, 1983; Stefanis et al, 1986). Community-based mental health services were underdeveloped and there were no psychiatric units in general hospitals. Thus, mental health services could not meet the needs of the population (Madianos et al, 1993).

The urgent need to establish psychiatric units in general hospitals and to improve psychiatric education, as well as for more specialised training, full utilisation of other mental health professionals and revision of mental health legislation, had been stressed since at least 1970 (Christodoulou, 1970).

\section{Reform}

Reform of mental healthcare became imperative in 1983 within the context of planning for the new National Health System in Greece. Law 1397/83, especially article 21, provided the basis for the decentralisation of psychiatric services (Sarantidis et al, 1992; Madianos et al, 1999a).

The Greek government undertook revision of the psychiatric care system by developing a 5-year plan. As part of the response to a request from the Greek government for financial support, EEC Regulation 815/84, Programme B, was adopted in 1984 and provided a grant of 120 million ECU. The strategic objectives of the 5-year plan (1984-89) in fact extended beyond 1989, up to 1995, and emphasised decentralisation of mental health services and the development of community-based services, deinstitutionalisation of 
Table 1 Numbers of patients in public mental hospitals, 1984-2006

$\begin{array}{lllllllllll} & 1984 & 1987 & 1990 & 1993 & 1996 & 2000 & 2004 & \begin{array}{c}2006 \\ \% \text { change, } \\ 1984-2006\end{array} \\ & & & & & & & & & \\ \text { Total number of patients (1-day census) } & 7487 & 7370 & 6504 & 5770 & 4765 & 3315 & 2564 & 2022 & -73.0 \\ \text { Number of long-stay patients (stay > 36 months) } & 5677 & 4925 & 4408 & 3747 & 3062 & 2922 & 1898 & 1091 & -80.8 \\ \text { Proportion of patients who were long stay, \% } & 75.8 & 66.8 & 67.8 & 64.9 & 64.3 & 88.1 & 74.0 & 54.0 & \end{array}$

long-stay patients and improvement of conditions in the public mental hospitals, with special attention to the Leros Mental Hospital (Bouras et al, 1992; Christodoulou et al, 1994, 1999; Zissi \& Barry, 1997). In 1989, the Hellenic Psychiatric Association, following an evaluation by a task force, prepared a comprehensive report on the Leros asylum (Hellenic Psychiatric Association, 1989) and made a number of recommendations to the Greek Ministry of Health. One of these was the placement of a substantial number of patients, after appropriate preparation, in sheltered housing on the mainland. This was implemented by the Ministry with the financial and technical assistance of the European Union (EU) in 1990 and heralded the deinstitutionalisation of a great number of the then 1150 chronic patients at the asylum (Christodoulou et al, 1999).

In 1997 a new multidimensional programme for the completion of the psychiatric reform, named Psychargos, was submitted to the EU and approved in 1998. This programme is divided into three phases: A, 1998-2001; B, 2002-06; and C, 2006-15. The main goal of the programme is the deinstitutionalisation of the remaining 3000 long-stay patients, with a parallel development of a total of 616 mental health services, residential alternatives and rehabilitation units.

This paper examines the first strategic objective of the 20 year psychiatric reform programme: the deinstitutionalisation of the long-stay patients in the nine public mental hospitals and the shift to extramural care and rehabilitation.

\section{The setting}

Greece has a total area of $132000 \mathrm{~km}^{2}$. In the 2001 census the total population was found to be 10939605 , of whom 3756607 lived in the Athens metropolitan area. The majority of the population (60\%) live in urban areas and the rest $(40 \%)$ in semi-urban and rural areas. In this census, some 800000 persons were identified as foreign immigrants, mainly from Albania, Bulgaria, Poland, other Balkan countries and the Middle East. The age distribution of the population was as follows: 0-14 years, $16 \%$; 15-64 years, 68\%; and 65 years and over, $18 \%$. In that census, $48 \%$ of the population were classified as dependent persons.

Administratively, the country has 54 prefectures (Nomos) and 13 regions (each region consists of several prefectures). It should be noted that, in the majority of regions, the main towns of the prefectures are not far from the capitals of each region.

The social security system covers $100 \%$ of the population for illness and 95\% for disability and old age pensions. In 1995 the employment make-up by the main sectors of economic activity was found to be agriculture $21 \%$, industry $29 \%$, services $46 \%$ and administration $5 \%$. The unemployment rate in 2003 was $10.8 \%$ of the labour force.

\section{The study}

To explore the effect of the psychiatric reform programme on patterns of psychiatric care, the following two groups of indicators were selected:

O quantitative trends (1984-2006) in the development of decentralised services and their regionalisation

o mental hospital in-patient population censuses.

Data that cover the period 1984-2006 concerning the establishment of new decentralised mental health services were obtained from DATAPSY, a database constructed by the Monitoring and Evaluation of Mental Health Services Unit (MEMHSU) on behalf of the Department of Mental Health of the Ministry of Health and Welfare. These data relate to: psychiatric bed numbers in general hospitals; various types of extramural services; the numbers of places in day hospital/ care facilities and psychosocial rehabilitation services; and the numbers of beds in residential alternatives. Population-based ratios were computed on the basis of the 1971, 1981, 1991 and 2001 population censuses.

\section{Findings}

The number of long-stay patients in public mental hospitals between 1984 and 2006 decreased by $80.8 \%$ and the total number of patients was reduced by $73.0 \%$ (Table 1 ).

In Table 2, the trends in the numbers of patients in eight of the remaining public mental hospitals over the period 1984-2006, and projected to 2012, are shown. In 1984 and 2006 , the numbers of patients in a day's census in all public mental hospitals were 7487 and 2022 respectively. Three mental hospitals were closed in 2006 and by the end of the same year another hospital was due to have been closed. By 2012, three more mental hospitals are due to be closed. By then there will be only 130 long-stay (geriatric) patients, at the Leros Mental Hospital, living in small pavilions.

Table 2 Trends in the public mental hospital population and planning for mental hospital closure, 1984-2012

$\begin{array}{lrrrcl}\text { Mental hospital } & 1984 & 2000 & 2004 & 2006 & 2012 \\ \text { Attica } & 1950 & 831 & 640 & 728 & \text { To be closed } \\ \text { Dromokaition } & 880 & 555 & 419 & 493 & \text { To be closed } \\ \text { Thessalonica } & 1000 & 581 & 526 & 254 & \text { To be closed } \\ \text { Petra Olympou } & 500 & 260 & 51 & \text { Closed } & - \\ \text { Chania (Crete) } & 416 & 250 & 167 & \text { Closed } & - \\ \text { Corfu } & 416 & 280 & 120 & \text { Closed } & - \\ \text { Leros }^{\text {Tripolis }}{ }^{1} & 1905 & 538 & 495 & 469 & 130 \\ \text { Total }^{420} & 220 & 124 & 78 & - \\ & 7487 & 3515 & 2542 & 2022 & 130\end{array}$

Note: Eginition University Hospital beds (60) are not included. 1. To be closed by the end of 2006 . 
Table 3 Alternative mental health services: numbers of psychiatric beds in general hospitals, extramural facilities and psychosocial rehabilitation places and residential beds, 1984-2006

\begin{tabular}{|c|c|c|c|c|c|c|c|c|}
\hline & 1984 & 1987 & 1990 & 1993 & 1996 & 1999 & 2006 & $\begin{array}{l}\% \text { change, } \\
1984-2006\end{array}$ \\
\hline Number of beds in general hospitals & 36 & 99 & 281 & 306 & 327 & 407 & 646 & +1694.5 \\
\hline Number per 1000 population ${ }^{1}$ & 0.004 & 0.01 & 0.03 & 0.03 & 0.03 & 0.03 & 0.06 & \\
\hline Number of community mental health centres ${ }^{2}$ & 7 & 15 & 19 & 23 & 33 & 41 & $45^{3}$ & +542.8 \\
\hline Number of child guidance clinics & 8 & 12 & 22 & 24 & 24 & 28 & 30 & +275.0 \\
\hline Number of out-patient departments in general hospitals & 20 & 38 & 43 & 51 & 56 & 56 & 70 & +250.0 \\
\hline Total number of extramural services & 35 & 65 & 84 & 98 & 113 & 125 & 145 & +314.3 \\
\hline Number per 100000 population & 0.34 & 0.63 & 0.81 & 0.95 & 1.10 & 1.20 & 1.32 & \\
\hline Number of places in day hospitals/care centres & 55 & 295 & 258 & 381 & 369 & 390 & 941 & +1610.9 \\
\hline Number per 1000 population & 0.005 & 0.02 & 0.02 & 0.04 & 0.04 & 0.04 & 0.08 & \\
\hline Number of places in psychosocial rehabilitation services & 195 & 315 & 779 & 1603 & 1643 & 1780 & 3080 & +1479.5 \\
\hline Number per 1000 population & 0.01 & 0.02 & 0.06 & 0.1 & 0.2 & 0.2 & 0.3 & \\
\hline Number of beds in residential alternative facilities & 15 & 25 & 359 & 540 & 1052 & 1962 & 4026 & +2674.0 \\
\hline Number per 1000 population & 0.001 & 0.002 & 0.03 & 0.05 & 0.1 & 0.2 & 0.3 & \\
\hline
\end{tabular}

${ }^{1}$ Psychiatric beds in general hospitals, extramural facilities, and psychosocial rehabilitation places and residential beds (per 1000 population). ${ }^{2}$ Fifteen community mental health centres also provide services for children and adolescents by multiprofessional teams.

${ }^{3}$ Thirty-four in operation.

It should be noted that the number of beds in the private mental hospitals decreased from 4817 in 1984 to 4007 in 2006. There is no provision for their future increase.

With regard to the length of stay in mental hospital, there was a significant reduction (78.5\%) in the average number of in-patient days between 1984 and 2003. During the same period, a gradual development of community-based mental health services of all types took place (Table 3). The number of psychiatric beds in general hospitals reached 646 in 2006, whereas there had been only 36 in 1984 . However, the corresponding population-based ratio is still low, at 0.06 beds per 1000 inhabitants.

Extramural facilities, including community mental health centres, child guidance clinics and out-patient departments, showed an enormous increase in number. In 1984 there were only 7 community mental health centres, but there were 19 in 1990 and 45 by 2006. Similarly, the number of child guidance clinics increased by 275\% between 1984 and 2006 (Table 3). There was also a marked increase in the number of mental health personnel working in the extramural services.

The increase in the total numbers of extramural facilities is also reflected in their increased ratios per 100000 inhabitants: from 0.34 in 1984 to 1.32 in 2006. Places in day hospitals, psychosocial rehabilitation services and residential alternatives were also dramatically increased, or even created where previously there were none. However, the number of places in day hospitals per 1000 inhabitants still appears to be low compared with the population-based ratios in other rehabilitation facilities.

With respect to the regional variations in the establishment of alternative mental health services, although the majority of facilities were established in Athens and other big cities, significant numbers of mental health services of various types have been established throughout Greece.

\section{Comment}

It appears that between 1984 and 2006 profound changes took place in the mental health scene, especially in the public mental hospital sector. The data presented above provide quantitative evidence of progress in the following areas:
O transformation of the public mental hospitals, with the parallel deinstitutionalisation of long-stay patients (Madianos et al, 1999b)

o decentralisation of the mental health services by provision of community-based structures, especially alternatives for community placement of discharged long-stay patients (Zissi \& Barry, 1997; Madianos, 2002).

In fact, the implementation of EEC Regulation 815/84, Programme B, within the period 1984-95, and the new Psychoargos programme have contributed to the gradual discharge of thousands of psychiatric patients. Nationwide, the programme provided the possibility of immediate deinstitutionalisation of 889 patients through placement in 68 hostels and sheltered apartments, between 1999 and 2001. It is of note that the programme contributed to a significant shift towards extramural care and rehabilitation, with a total of 264 services in 1995.

The reduction in the number of beds in public mental hospitals has not been accompanied by an increase in the number of beds in private psychiatric hospitals, where a reduction has also been recorded. A similar finding was reported by Tansella et al (1987) in Italy.

By 2006 the number of long-stay patients was found have fallen to 1091, from 5677 in 1984; obviously, these hundreds of patients will require further rehabilitation and community integration. It is true, for example, that few of the patients who receive occupational rehabilitation training eventually find a job consistent with the training they have received. In fact, most patients do not find a job at all, for a variety of reasons, including the high unemployment rate, particularly in the 25- to 30-year age-group.

Finally, the closure of the public mental health hospitals within 10 years, a policy already practised in other European countries (Thornicroft \& Bebbington, 1989; Hall \& Brockington, 1991), seems to be realistic. In addition, legislation (Law 2716/99) on the sectorisation of mental health services has introduced the basic legal and managerial framework for the completion of the psychiatric reform.

In conclusion, it is evident that public health psychiatry in Greece has made significant progress in the areas of deinstitutionalisation, decentralisation and rehabilitation. It is widely accepted that implementation of the psychiatric reform programme (1984-2006), despite some inadequacies and 
constraints, has had a significant, positive impact on mental health. On the other hand, much remains to be done in the areas of primary care, prevention, integration of psychiatric and medical services, evaluation of the quality of extramural services and the quality of life of the patients in these services.

\section{References}

Athens Mental Health Promotion Project (2003) WPA Sections Newsletter, issue 6, p. 4.

Bouras, N., Webb, Y., Clifford, P., et al (1992) A needs survey among patients in Leros asylum. British Journal of Psychiatry, 161, 75-79.

Christodoulou, G. N. (1970) Psychiatry in Greece. International Journal of Social Psychiatry, 16, 314-316.

Christodoulou, G. N., Kontaxakis, V. P., Havaki-Kontaxaki, B. J., et al (1994) Leros deinstitutionalization program: psychopathological parameters in sheltered care residents. In Topics in Preventive Psychiatry (eds G. N. Christodoulou \& V. P. Kontaxakis), pp. 116-124. Karger.

Christodoulou, G. N., Kontaxakis, V. P., Havaki-Kontaxaki, B., et al (1999) From the Leros asylum to sheltered housing in the community. In Issues in Preventive Psychiatry (eds G. N. Christodoulou, D. LecicTosevski \& V. P. Kontaxakis), pp. 83-89. Karger.

Hall, P. \& Brockington, I. F. (eds) (1991) The Closure of Mental Hospitals. Gaskell.

Hellenic Psychiatric Association (1989) Report on the issue of Leros. Psychiatriki, 1, 183-189.
Madianos, M. (1983) Mental illness and mental health care in Greece. Public Health Reviews, 11, 73-93.

Madianos, M. (2002) Deinstitutionalization and the closure of public mental hospitals. International Journal of Mental Health, 31, 66-75.

Madianos, M., Madianou, D. \& Stefanis, C. (1993) Help-seeking behavior of psychiatric disorders from physicians and psychiatrists in Greece. Social Psychiatry and Psychiatric Epidemiology, 28, 285-291.

Madianos, M., Tsiantis, C. \& Zacharakis, C. (1999a) Changing patterns of mental health care in Greece (1984-1996). European Psychiatry, 14, 462.

Madianos, M., Zacharakis, C., Tsitsa, C., et al (1999b) Geographical variation in mental hospital discharges in Greece and socio-economic correlates: a nationwide study (1978-1993). Social Psychiatry and Psychiatric Epidemiology, 34, 477-483.

Sarantidis, D., Kladouchos, V., Tripodianakis, J., et al (1992) The reform of psychiatric care in Greece. European Psychiatry, 7, 251-257.

Stefanis, C., Madianos, M. \& Gittelman, M. (1986) Recent developments in the care, treatment, and rehabilitation of the chronic mentally ill in Greece. Hospital and Community Psychiatry, 37, 1041-1044.

Tansella, M., De Salvia, D. \& Williams, P. (1987) The Italian psychiatric reform: some quantitative evidence. Social Psychiatry and Psychiatric Epidemiology, 22, 37-48.

Thornicroft, G. \& Bebbington, P. (1989) Deinstitutionalisation - from hospital closure to service development. British Journal of Psychiatry, 155, 739-753.

Zissi, A. \& Barry, M. (1997) From Leros asylum to community-based facilities: levels of functioning and quality of life among hostel residents in Greece. International Journal of Social Psychiatry, 43, 104-108.

\title{
Attitudes towards mental illness in Uganda: a survey in 18 districts
}

\section{Vuokko Wallace ${ }^{1}$ MSc, Jed Boardman ${ }^{2}$ PhD FRCPsych and James Walsh ${ }^{3}$ PhD}

\author{
'Trainee Clinical Psychologist, School of Psychology, University of East London, UK \\ ${ }^{2}$ Senior Lecturer in Social Psychiatry, Health Services Research Department, Institute of Psychiatry, London, UK \\ ${ }^{3}$ Senior Lecturer in Psychology, School of Psychology, University of East London, London, UK
}

U Aft ganda, in common with many countries in sub-Saharan Africa, has many population risk factors predictive of high levels of mental disorder but poor coverage of mental healthcare (Kigozi, 2005). Recent population studies conducted in Uganda have shown rates of disorder in excess of 20\% (Kasoro et al, 2002; Bolton et al, 2004; Ovuga et al, 2005) and the survey by Kasoro et al (2002) showed a high prevalence of patients with severe mental illness and poor access to services. There are 19 psychiatrists for 24.8 million people in Uganda, all but one of whom is based in the capital city, Kampala (Kigozi, 2005). The provision of mental health services relies on the use of psychiatric clinical officers (a cadre of trained mental health workers, similar to community psychiatric nurses, who currently cover 18 of the 56 districts in Uganda), primary care personnel, non-governmental organisations and members of the community. Liaison with traditional healers is encouraged (Ovuga et al, 1999).

In addition to poor access to services, it is possible that ignorance and stigma prevent people with mental illness from seeking appropriate help, and that community attitudes and beliefs play a role in determining help-seeking behaviour, as well as the success of treatment (Hugo et al, 2003). A strong element in the culture of Uganda is the collective nature of the people and this can be utilised in enhancing services. In order to develop mental health policy and services in Uganda, there is a need to establish a series of estimates of the extent of psychiatric disorder and knowledge of local idioms, beliefs and management (Boardman \& Ovuga, 1997). The aim of this study was to examine community attitudes toward mental illness in urban and rural Uganda.

\section{Methods}

The study was carried out in 2002-03, when one of the authors (V.W.) was working as a visiting psychology lecturer at Mbarara University of Science and Technology. The study was a cross-sectional survey exploring attitudes towards 